\title{
O MOVIMENTO DAS EMOÇÕES NA VIDA DOS IDOSOS: UM ESTUDO COM UM GRUPO DA TERCEIRA IDADE
}

\author{
THE MOVING OF EMOTION ON ELDERLY' S LIFE: A STUDY WITH A THIRD AGE GROUP
}

\section{EL MOVIMIENTO DE LAS EMOCIONES EN LA VIDA DE LOS ANCIANOS: UN ESTUDIO CON UN GRUPO DE LA TERCERA EDAD}

\section{Fabíola Braz Penna ${ }^{1}$, Fátima Helena do Espírito Santo ${ }^{2}$}

RESUMO: Estudo qualitativo cujos objetivos foram descrever as emoções na vida do idoso e discutir a relação entre emoções e saúde do idoso. O estudo foi desenvolvido em um grupo da terceira idade no município de São Gonçalo/RJ através de observação participante e entrevistas semiestruturadas com dez idosos. Após análise das informações identificamos a categoria O Pêndulo das Emoções com dois temas complementares: movimento ascendente e movimento descendente das emoções no viver. Os idosos evidenciaram que suas emoções representam um movimento contínuo que repercute diretamente na sensação de estar ou não com saúde e viver bem a terceira idade, é ter autonomia nas atividades diárias e liberdade para participar de atividades físicas e de lazer. Assim, o ser humano precisa valorizar todas as etapas de sua vida, pois o processo de envelhecimento começa a partir do momento em que nascemos e a qualidade de vida é uma conquista diária nessa caminhada.

PALAVRAS-CHAVE: Envelhecimento; Saúde Mental; Qualidade de vida.

ABSTRACT: Qualitative study which aims was to describe the emotions in elderly life and to debate the relation between emotions and elderly health. The study was developed in a third age group at Sao Gonçalo city - RJ by participant observation and semi-structured interviews with ten elderly people. After the information analysis it was possible to identify the category "The Pendulum of Emotions" and two complementary subjects: rising and descending movement of emotions on living. The elderly evidenced that their emotions represents a continuous movement which reflects straightly to the feeling of being or not healthy and living well the third age is having autonomy of daily activities and freedom to participate of leisure and physical activities. Thus, the human being needs to valorize all the stages of his life, because the process of becoming old starts from the moment we were born and the quality of life is a daily conquest in this way.

KEY WORDS: Aging; Mental Health; Quality of Life.

RESUMEN: Estudio cualitativo cuyos objetivos fueron describir las emociones en la vida del anciano y debatir la relación entre las emociones y la salud del anciano. El estudio fue desarrollado en un grupo de la tercera edad en la ciudad de São Gonçalo, RJ, por medio de observación participante y entrevistas semi estructuradas con diez ancianos. En la análisis de las informaciones fue posible identificar la categoría: "el péndulo de las emociones" con dos temas complementarios: movimiento ascendiente y movimiento descendiente de las emociones en el vivir. Los ancianos evidenciaron que sus emociones representan un movimiento continuo que hace repercusión directamente en la sensación de estar o no con salud, y vivir bien en la tercera edad es tener autonomía en las actividades cotidianas y libertad para participar de actividades físicas y ocio. Así, el ser humano necesita valorar todas las etapas de su vida, pues el proceso de envejecimiento empieza a partir del momento en que nacemos y la cualidad de vida es una conquista de todos los días en esta caminada.

PALABRAS CLAVE: Envejecimiento; Salud Mental; Calidad de vida.

\footnotetext{
${ }^{1}$ Enfermeira. Especialista em Enfermagem do Trabalho pela Escola de Enfermagem Aurora de Afonso Costa da Universidade Federal Fluminense (EEAAC/UFF). Enfermeira Residente em Saúde Pública pela Escola de Enfermagem Alfredo Pinto da Universidade do Rio de Janeiro, RJ (EEAP/UNIRIO). E-mail: biabrazpenna@gigalink.com.br.

Enfermeira. Professora Adjunta do Departamento de Enfermagem Médico-Cirúrgica da EEAAC/UFF. Doutora em Enfermagem pela Escola de Enfermagem Anna Nery da Universidade Federal do Rio de Janeiro - /UFRJ. E-mail: professorafh@bol.com.br
} 


\section{NTRODUÇÃO}

O presente artigo foi elaborado a partir do trabalho de conclusão de curso o qual seguiu os parâmetros da instituição acadêmica para obtenção do titulo de enfermeiro e licenciado em enfermagem (PENNA, 2004).

Nos últimos anos observa-se um aumento significativo de estudos abordando o processo de envelhecimento e suas repercussões na saúde do idoso, comprovando a relevância e o movimento crescente de conscientização acerca da necessidade de um maior conhecimento das especificidades do idoso, nos aspectos biológico, social, cultural e econômico para rompermos com os estereótipos e preconceitos que ainda isolam e excluem estes indivíduos na sociedade. Este aumento da expectativa de vida, principalmente nos países desenvolvidos, tem íntima relação com fatores tais como: alimentação, habitação, saneamento básico, educação, mudanças nos padrões reprodutivos, desenvolvimento tecnológico e avanços no controle e tratamento de doenças. Logo, a mudança da pirâmide populacional, nas últimas décadas, está associada à redução da mortalidade de adultos e idosos e a diminuição da taxa de fertilidade (PAPALEO NETTO, 1994).

A partir dessa transformação no âmbito da saúde, os profissionais começam a investir mais nesta clientela, principalmente no setor de atenção primária. O atendimento geriátrico e gerontológico, pode ser definido como um processo interdisciplinar que atende as pessoas idosas, visando os serviços médicos, psicológicos, social e funcional a fim de manter o idoso com plena capacidade e autonomia pelo maior período possível. Mas, nesse contexto, é preciso considerar que a saúde é algo a ser conquistado e não dado, o que envolve esforço e investimento para mantê-la (PAPALEO NETTO, 1994).

Nesse sentido, TEIXEIRA (1988, P. 91) argumenta que:

"ao mesmo tempo em que o cuidado depende do indivíduo, ele também tem uma dimensão que escapa à boa vontade consciente, pois passa pelo econômico, pelo inconsciente, pelas produções capitalistas de subjetividade com o corpo. O cuidado é também resultante dos equipamentos coletivos que produzem subjetividade, e o sujeito, quando fala do cuidado, fala também do seu salário, de sua família, dos seus sentimentos e dos seus desejos".

Entretanto, quando a pessoa envelhece existem alguns fatores psicossociais que interferem na qualidade de vida como a perda da posição social comum após a aposentadoria, a pobreza que dificulta as condições mínimas de sobrevivência e, conseqüentemente, limita a participação dos idosos em eventos sociais, a solidão, pois muitas vezes os idosos têm pouco contato com outras pessoas devido à dificuldade de transporte adequado, problemas financeiros, incapacidade física e falta de companhia associada ao medo e a perda de amigos, parentes, cônjuges. Tudo isso pode levar o idoso à depressão e a uma maior dependência, física e/ou psicossocial.

Além dos fatores psicossociais que interferem no processo de envelhecimento, existe ainda a relação do indivíduo com a sociedade. Sendo assim, os idosos, muitas vezes, sentem-se inferiorizados pela sociedade, principalmente após a aposentadoria, quando tendem a ser considerados inúteis $e$ improdutivos, pois, além de conviver com uma série de mudanças orgânicas, sentem-se como um peso para seus familiares e amigos o que acaba gerando seu isolamento do convívio social como forma de preservação.

Assim, a velhice pode ser caracterizada pela maneira como a sociedade determina e encara o envelhecer, sendo mais forte do que a percepção do idoso a respeito do envelhecimento o que nem sempre corresponde ao seu estado de velhice. Por isso, a forma como uma sociedade superprotege, venera ou marginaliza o idoso determinará como ele vai se adaptar e assumir a velhice (WALDOW, 1998). Portanto, envelhecer de forma saudável implica, não apenas na possibilidade dos idosos disporem de cuidados em relação aos problemas de saúde mais comuns nesta etapa da vida, mas, também, no reconhecimento das suas possibilidades e necessidades específicas. Significa que, além de bom estado de saúde física eles necessitam de respeito, segurança e, principalmente, precisam sentir-se ativos em sua comunidade com oportunidade de expressarem livremente seus sentimentos, emoções, interesses, opiniões e experiências.

Algumas pesquisas demonstram que a principal tarefa evolutiva da velhice é a integração social e a autonomia pessoal; "a segurança propiciada por um ambiente acolhedor, assim como a autonomia permitida por um ambiente estimulador são ambas, necessárias ao bem-estar do idoso" (TEIXEIRA, 2002, p.105). É bem verdade que o idoso convive com limitações da própria idade, as quais podem prejudicar sua independência e autonomia para desenvolver determinadas atividades. Mas, é preciso que ele seja estimulado $a$, inicialmente, organizar seu tempo fazendo projetos de vida com criatividade, energia e iniciativa isto é, dando significados a vida para que esta não caia no vazio (LIMA, 2000).

Nesse sentido, podemos considerar que às atividades de lazer e a convivência em grupo contribuem tanto para a manutenção do equilíbrio biopsicossocial do idoso, quanto para atenuar possíveis conflitos ambientais e pessoais. Por isso, é 
importante para o ser humano a atividade física, intelectual e de lazer, pois, em todas as etapas da vida devemos nos preocupar com as perspectivas de um envelhecimento saudável. E nesse sentido, para se qualificar a vida é necessário comparar o passado e o presente, as coisas boas e ruins, a infância, a juventude, a maturidade e a velhice em um contexto social e histórico (LÓPEZ \& CIANCIARULLO, 1999).

Assim, a compreensão de qualidade de vida na velhice está atrelada ao significado de velhice dada pelos idosos onde devem ser consideradas as referências às mudanças do corpo e as imagens desse corpo, os contrastes sociais e culturais que caracterizam o curso de vida, se o passado foi marcado pela busca de sobrevivência, pelo trabalho com poucas garantias ou não, e se hoje na velhice, sobrevivem com a ajuda de familiares ou são independentes. $O$ envelhecimento bem-sucedido não é um privilégio ou sorte, mas um objetivo a ser alcançado por quem planeja e trabalha para isso, sabendo lidar com as mudanças que efetivamente acompanham o envelhecer.

Além da maneira como o idoso lida com as mudanças ocorridas nessa fase da vida, a qualidade de vida envolve também seus hábitos de vida e isso inclui as atividades de lazer. Além disso, falar de qualidade de vida é considerar também as emoções e suas repercussões para a saúde.

Há alguns anos, afirmar que existia uma vinculação direta entre o estado emocional e a boa saúde era quase um contra-senso para a ciência, mas isso se devia em parte ao conceito que se dava à saúde e que em determinadas sociedades ainda é cultuado, a visão biologizada, que se entende como sendo ausência de doença quando o organismo encontra-se em bom estado geral, sem alterações patológicas. A saúde foi definida pela Organização Mundial da Saúde (OMS) em 1948, como um estado de completo bem-estar físico, mental e social e não apenas a ausência da afecção ou doença.

Nesse bem estar destacamos a emoção que refere-se ao sentimento e seus pensamentos distintos, estados psicológicos e biológicos. As emoções são essencialmente impulsos para agir e lidar com as situações da vida e sofrem influência das experiências vivenciadas e da cultura (GOLEMAN, 2001). Existem centenas de emoções, juntamente com suas combinações, variações, mutações e matizes tais como: ira, tristeza, medo, prazer, amor, surpresa, nojo e vergonha. O momento da emoção é o momento em que tocamos a nossa força vital, reencontramos a nossa origem, os ancestrais, a nossa história coletiva e pessoal (GAUTHIER, 1999).

A evolução da medicina sobre a existência de substâncias químicas atuando no metabolismo cerebral capazes de alterar o estado emocional e, conseqüentemente, a saúde resultou nos conhecimentos atuais sobre os neurotransmissores e neuroreceptores relacionados à atividade cerebral dos quais, destaca-se a serotonina e sua relação com a sensação de bem-estar das pessoas (BALLONE, 2002). Nesse sentido, algumas pesquisas que procuraram embasar a teoria de que a depressão seria conseqüente a baixos níveis da serotonina $\mathrm{e}$ quando se fala em idoso, a depressão é algo que vem sendo estudada e discutida nos últimos anos.

A depressão no idoso apresenta-se de forma mais habitual com os quadros pouco sintomáticos e de evolução lenta, que se associam com alterações hormonais, consumo de medicamentos por iniciativa própria, como anti-hipertensivos, ansiolíticos e hipnóticos, e com situações de solidão e perda, como a morte do parceiro, a falta de apoio social ou familiar, uma mudança ou uma internação em uma instituição (RUIPÉREZ \& LLORENT, 1996).

A depressão possui fator de hereditariedade $e$ hormonal, mas pode ter causas psicossociais também. diz que a perda da auto-estima no processo de envelhecimento está associada ao quadro depressivo do idoso decorrente do forte sentimento de dependência e perda crescente da autonomia (RUIPÉREZ \& LLORENT, 1996; OLIVEIRA, 2003) .Nesse contexto, ao perceber que não pode mais agir como antes sobre o mundo, a pessoa idosa ao que parece, não vê outra escolha senão retirar-se do mundo, mergulhando pouco a pouco em um profundo estado de depressão (RUSCHEL, 2001).

Porém, elementos tais como amor, humor, surpresa, curiosidade, paixão, perdão, alegria, esperança, entusiasmo, dar e partilhar atuam no sistema imunológico ajudando nosso corpo a combater infecções e estimulando células naturais que combatem o câncer e afetam a forma com que cuidamos de nós mesmos e dos outros. Por outro lado, quando raiva, ressentimento, ambivalência, culpa, tédio, solidão e medo são reprimidos durante muito tempo, podem suprimir nosso sistema natural de proteção e nos fazer sentir mal. (ADAMS, 1998). Isso quer dizer que as emoções desencadeiam reações físicas e atualmente, a medicina em geral, e particularmente a psiquiatria, enfatizam a importância do bom humor, dos bons sentimentos e da afetividade sadia na qualidade de vida e na saúde global da pessoa, pois os efeitos do bom humor sobre a saúde física são tão evidentes que uma boa e sincera risada pode ter a importância de uma sessão de ginástica (BALLONE, 2002).

O bem-estar proporcionado pela participação do idoso em atividades em grupo contribui não só para a sua conscientização sobre a importância do autocuidado mas também oportuniza a vivencia e troca de experiências que repletas de emoções que movimentam suas vidas, gerando uma sensação de bem estar. Essas sensações de bem-estar podem ser discutidas à luz de uma abordagem holística, que integra funções físicas, emocionais e espirituais. Assim, como essas funções estão inter-relacionados, qualquer mudança em uma delas pode causar 
repercussões nas outras. Estas são mudanças positivas que demonstram que o todo é maior do que a soma de suas partes (VICINI, 2002). Nesse sentido, o aumento da expectativa e a qualidade de vida das pessoas idosas podem estar associados não somente a evolução da tecnologia e medicina, mas, também, à vivência dos idosos em grupos a qual transcende as atividades físicas e de lazer. Nesses grupos os idosos compartilham e expressam emoções, apesar de muitos serem portadores de doenças comuns nessa faixa etária, tais como hipertensão arterial e diabetes mellitus, dentre outras.

À luz dessas considerações, esse estudo teve como objetivos descrever as emoções na vida do idoso e discutir a relação das mesmas com a saúde desse idoso.

\section{METODOLOGIA}

O estudo de natureza qualitativa foi realizado junto ao grupo da terceira idade do Projeto Multidisciplinar de Valorização do Idoso organizado pelo Pró-Saúde, Serviço Social do Comércio (SESC) situado no município de São Gonçalo, no Estado do Rio de Janeiro e os sujeitos foram 10 (dez) idosos com idade superior a 60 anos que mostraram interesse e disponibilidade para participar do estudo.

Após autorização da instituição para realização do estudo, como preconizado na Resolução CEP 196//96, a coleta de informações foi desenvolvida em duas etapas, no período de abril a agosto de 2003. $\mathrm{Na}$ primeira etapa, foi desenvolvida a observação participante, com registros em diário de campo, visando à aproximação do pesquisador com o cenário e os sujeitos do estudo. Na segunda etapa da coleta de informações, após esclarecimento dos objetivos do estudo e assinatura do termo de consentimento livre esclarecido, foram realizadas entrevistas semiestruturadas, gravadas em fitas magnéticas para preservar o conteúdo integral dos discursos.

De posse das informações, as entrevistas foram transcritas na íntegra, digitadas e identificadas com nomes fictícios. Após diversas leituras das informações identificamos os temas comuns que foram agrupados na categoria $O$ Pêndulo das Emoções com dois temas complementares: movimento ascendente e movimento descendente das emoções no viver. Consideramos aqui as emoções, como algo que está sempre se movimentando e que, dependendo dos acontecimentos da vida sofrem movimentos que fazem bem, que levam o sujeito a se expressar, viver, buscar (movimento ascendente) e que fazem mal, que levam o sujeito a se interiorizar, isolar-se (movimento descendente).

\section{RESULTADOS E DISCUSSÃO}

Ao iniciar o estudo meu propósito era conhecer de perto um grupo da terceira idade, a fim de saber como os idosos desenvolviam suas atividades no grupo, viviam e interpretavam suas experiências e, mais que isso, pretendia compreender como eles compartilhavam e expressavam suas emoções.

O grupo possuía cerca de 30 participantes, dos quais a maioria tinha entre 60 e 64 anos. A maioria dos participantes era do sexo feminino, casadas e não trabalhavam. Em relação à religião 23 eram católicos. 17 idosos possuíam ensino fundamental completo e todos eram moradores de São Gonçalo, já que este era um requisito para a participação no Projeto. Dos idosos, 12 residiam com os cônjuges e apenas 4 moravam sozinhos. Eles relataram que o principal motivo que os levaram a procurar o grupo foi indicação médica e que suas atividades de lazer preferidas eram: viajar, participar de encontros familiares e ir à igreja. Dos 30 idosos, 28 faziam uso de medicamentos. A doença predominante nos participantes do grupo era a Hipertensão Arterial.

\section{O Pêndulo das Emoções}

Para os idosos do grupo alguns informaram possuir "qualidade de vida boa" mas, alguns complementaram dizendo que qualidade de vida é ter saúde através de "uma boa alimentação, atividade física, prazer em viver, atividades de lazer, convívio com a família unida, seguir uma religião e ter caráter, sendo honesto". Segundo NÉRI (2000, p. 12-13), a qualidade de vida para os idosos pode ser entendida como envelhecer de forma satisfatória e isso "depende do delicado equilíbrio entre as limitações e as potencialidades do indivíduo, o qual the possibilitará lidar, em diferentes graus de eficácia, com as perdas inevitáveis do envelhecimento".

Várias foram as formas pelas quais os sujeitos desse estudo disseram ou expressaram o que eram e como eram as emoções em suas vidas. Um dos pontos mais presentes nos discursos foi a relação entre saúde e doença. A saúde foi associada com a ter independência, autonomia para desenvolver atividades diversas; comportamento de busca e de viver plenamente. Em contrapartida, a doença foi associada à dependência física ou emocional, às incapacidades e restrições que podem levar a um quadro de depressão, como ilustra a fala da Sra. Imagem:

"Eu era cheia de reumatismo. Eu agora tenho uma atividade danada, minha pressão controlou mais, graças a Deus, to me sentindo outra".

Sentindo-se isolado e triste, o Sr. Tempo desabafou seu desejo de receber mais atenção da família:

"Eu fico assim, se eu tivesse uma família maior, talvez eu tivesse mais apoio, talvez tivesse mais atenção, né?" 
Mas, reforçando uma relação entre saúde e bem estar, a Sra. Asa disse que quando estava bem emocionalmente, sentia-se mais disposta:

"Fico melhor, fico mais disposta, tenho mais ânimo pras coisas. Enfim, dá mais vontade de fazer isto ou aquilo."

Enfim, sejam boas ou ruins, as emoções estavam sempre em contínuo movimento, ascendendo ou descendendo. $O$ movimento ascendente foi associado pelos idosos como aquilo que causa bem estar, que impulsiona, que expande, que exterioriza, que expressa, que faz buscar o que a vida tem de melhor.

\section{Movimento Ascendente}

Estudos sobre desenvolvimento na meia-idade e na velhice, demonstram que a motivação, ou seja, aquilo que movimenta a pessoa em direção a algo é o que dá significado a vida e vai adquirindo significações diversas ao longo do desenvolvimento humano. Assim, para os idosos, a força motriz da busca de contatos está muito mais ligada a conteúdos emocionais e afetivos, do que a busca de informações, preponderantemente mais fortes nos jovens (VICINI, 2002) .

Para Sra. Fogo o sentimento de satisfação diz respeito à família da qual faz parte:

"Muito boa, porque é uma família unida, né?

Eu, meu marido, meus 2 filhos, casal de filhos, tenho meu genro que é espetacular, tenho minha nora que é excelente, tenho meus 4 netos que é uma maravilha"

O prazer também foi referido pelo Sr. Vento, como a forma ideal do bem viver em família:

"Para mim, as coisas básicas da vida são: viver com carinho com o outro, respeitando o outro; eu respeito ela e ela me respeita, viver com amor com ela, com os filhos, entendeu? É uma vida muito boa, muito gostosa".

Ser avó, vendo "os frutos dos seus frutos" nascerem e crescerem foi apontado como uma fonte de prazer pela Sra. Linha:

"Vivo com meu marido. Tenho 2 filhos, um solteiro e outro casado. Esse casado me deu o prazer de ser avó. Tenho uma netinha linda!"

A proximidade da família, de uma maneira geral, proporciona conforto e companhia ao idoso e, à medida que a idade avança, esta tende a tornar-se o centro das suas relações, proporcionando tanto ajuda e cuidados como companhia o que alivia a sensação de abandono e isolamento, causa importante de depressão na terceira idade (RUIPÉREZ \& LLORENT, 1996).

Viver uma boa velhice, significa viver um processo continuo de adaptação e aprendizagem com os ganhos e perdas em busca da integridade e do bem estar (NÉRI, 2000) e, para os idosos desse estudo, a participação no grupo representa uma possibilidade de viver melhor esse processo.
Segundo o Sr. Vento, dentre as atividades desenvolvidas no grupo de idosos, a ginástica é a que mais tem influenciado na melhoria da saúde dele e da sua esposa:

"Para mim foi bom, mas pra ela foi melhor ainda, porque ela tinha problema de artrose e melhorou muito".

Estudos demonstram que as atividades físicas melhoram o condicionamento físico, aumentando a capacidade funcional cardiovascular e diminuindo as necessidades miocárdicas de oxigênio. Além disso, está comprovada a relação entre exercício e o aumento da sensação de autoconfiança e autoestima, o que repercute em respostas cardiovasculares e humorais ao estresse mental (PORTELLA, 2004; BARBOSA, 1999).

Os benefícios apontados pelos idosos realmente não foram apenas físicos, mas, principalmente, psicológicos. Isso foi associado ao ambiente e a vivencia em grupo, como ilustra o relato da Sra. Luz:

"Ah traz muito benefício. Eu adoro minha ginástica, eu saio daqui revigorada. E benefício mental também. Os momentos que a gente passa aqui, a gente se distrai, a gente brinca, a gente, né? Espairece, né? Não é só física não, a mente também melhora".

Quanto ao ambiente da ginástica a Sra. Linha não mediu elogios, dizendo:

"E a ginástica? Tem coisa melhor? Eu adoro vir pra cá. A gente brinca, conta piada, o professor parece até um palhaço, faz a gente rir o tempo todo. É uma terapia, muito boa!"

A saúde do idoso está diretamente relacionada à sua capacidade de locomoção e sua saúde, o que preserva sua capacidade funcional, impedindo que ele se torne sedentário e dependente. Na convivência com o grupo, ficou evidenciado o quanto eles tinham orgulho de si mesmos por constantemente estarem sendo elogiados pelos familiares e médicos em face de prática de exercícios físicos. Além disso, eles sentiam-se valorizados no grupo, porque estavam se auto cuidando, buscando o convívio social fonte de prazer e saúde.

$\mathrm{O}$ autocuidado pode ser entendido como "o conjunto de medidas que tomam as pessoas para melhorar sua própria saúde e bem -estar no seio das suas atividades cotidianas". E, na perspectiva da saúde publica é entendido como "um comportamento social ativo que inclui o sentido de adição à competência e habilidade do ser humano" (KICKBUSCH, 1996, p. 240).

$\mathrm{O}$ fato deles se sentirem úteis, valorizados ficou evidenciado como fator que favorece a saúde deles como ilustra o depoimento do Sr. Tempo que referiu satisfação pela oportunidade de poder ajudar ao seu conterrâneo:

"Eu gosto de atender mais aquelas pessoas mais necessitadas, então eu tenho um 
conterrâneo e ele vive mais é de cadeira de rodas, porque encolheu o nervo, uma perna ficou mais curta que a outra, agora ta com efeito do Diabetes, né? E eu dou muita assistência a ele. Aí, todo mês eu ajudo a fazer as compras e eu me sinto bem com aquilo."

A relação que os idosos têm com as emoções e a saúde passa pela maneira com que eles vivenciavam suas emoções. Alguns inclusive deixaram bem claro em suas falas que agiam de uma forma bastante transparente tanto para emoções boas quanto ruins. A Sra. Luz revelou como expressava as emoções de forma transparente:

"Eu expresso as minhas emoções, porque eu sou assim muito aberta, né? Em tudo que eu faço, sou muito transparente."

Mas, não são as emoções em si que causam problemas. Os problemas são causados quando reprimimos as emoções durante horas, dias ou até mesmo anos (VICINI, 2002). O ser humano é um ser que tem sentimentos e é a sua capacidade de envolver-se, de afetar e de ser afetado pelo outro, que o torna humano. É esse sentimento, que se chama cuidado e se situa na lógica do afeto. O cuidado pressupõe uma relação, e essa relação não deve ser de domínio sobre o outro, mas de convivência. O cuidado se dá na "inter-ação e comunhão" É a partir do cuidado com o outro, que o ser humano desenvolve a dimensão de alteridade, de respeito, valores fundamentais da experiência humana. Assim, o cuidado se dá numa relação afetiva, e engloba o modo de ser do ser humano, em seus laços afetivos (BOFF, 1999).

\section{Movimento Descendente}

Ao termo descendente foi associado tudo aquilo que para o idoso interioriza, deprime, e faz adoecer. Se fotografássemos a natureza, iríamos perceber que nem todas as fotografias seriam repletas de flores coloridas, com dias ensolarados ou com crianças sorrindo cheias de esperança na vida que está apenas começando. Assim é a realidade da vida e das emoções na vida. Têm dias em que a chuva, os raios e trovoadas insistem em permanecer e não conseguimos acreditar que o sol irá reaparecer. Da mesma forma é a vida. Quando ocorrem momentos e épocas que são como as tempestades que destroem casas, estradas que pareciam tão sólidas e inabaláveis. Algumas vezes, os acontecimentos que a vida nos guarda causam o mesmo efeito. Para uns o dia seguinte é logo dia de reconstruir e superar mas, para outros não. Esses abalos foram associados primeiramente à aposentadoria.

Isso foi constatado no depoimento do Sr. Tempo que diante da aposentadoria começou a apresentar alteração da pressão arterial:

"Aí, quando eu me aposentei, eu me aposentei por idade, por tempo de serviço, né?(...) aí depois que me surgiu, porque eu nunca tinha tido problema de pressão, aí que me surgiu meu problema emocional."

Hoje em dia, pela própria demanda socioeconômica e com a longevidade, a aposentadoria deixou de ter espaço de premiação para adquirir um aspecto de punição. São raras as pessoas estarem preparadas para enfrentá-la, quer porque tendam a supervalorizar seus efeitos positivos, quer os negativos. Os que valorizam o lado positivo idealizam as vantagens do tempo livre que ela proporciona. Já para os que têm uma visão negativa, o mais comum é que percebam o afastamento do trabalho como a fronteira com a velhice, com toda a carga de preconceito a ela associada (SCHIFFERLE, 2003).

Outro elemento que causa efeito devastador na vida do idoso é a família embora pareça contraditório, mas ocorre quando a família ao invés de acolher, proteger e/ou integrar o idoso como membro participante e valorizado desta, age de maneira inversa, ou seja, isolando ou distanciando.

O Sr. Tempo em sua fala deixou bem claro como a distância de um familiar, de um filho gera um sentimento de isolamento:

"A parte que eu senti mais isolado, foi quando meu filho passou esses nove meses no exterior, né? (...) porque ele me dá muito apoio, apesar de ser o mais moço. Aí eu fiquei assim, com uma espécie de depressão. O esposo é formado pela Marinha, então ela (filha) vai pro cartório, aqui o fórum, eu praticamente fico só, né? Aí eu vou somente pra casa dela nas horas das refeições, mas fico mais na minha casa. Porque ela tem o compromisso dela com a família e eu não".

O distanciamento da filha é uma situação que para a Sra. Fogo é fonte de tristeza:

"Só que minha filha mora longe, né? Mora em Vila Velha" (olhos cheio de lágrimas).

Quando os filhos estão passando por algum problema, naturalmente, os pais sentem e alguns dos sujeitos deixaram bem claro que esses problemas afetam também a sua saúde e seu equilíbrio emocional. A Sra. Imagem comentou sobre a separação conjugal da sua filha:

"Ah, agora então eu tive uma muito ruim, minha filha ia fazer 25 anos de casada, separou do marido. (...) quer dizer isso foi um "back" que não foi mole." (expressão de tristeza)

O melhor lugar para o idoso é a sua própria casa junto com sua família, mas, muitas vezes, esse ambiente não proporciona tudo que ele necessita Assim, ele sente-se isolado, como se fosse uma despesa extra que causa desconforto aos demais membros e passa a maior parte do tempo sozinho, como se possuísse um mundo próprio onde ninguém o vê e acolhe. Ele muitas vezes, presencia situações problemáticas dentro do lar, com os filhos, netos, mas 
sente-se impotente para resolver os problemas que observa e vivencia de perto. Porém, como pai, mãe, avó ou avô ele sofre, e esse sofrimento transborda em mal estar, tristeza e alterações do seu estado de equilíbrio, fazendo o pêndulo movimentar-se em sentido descendente.

Ao chegar na terceira idade muitos sucessos e fracassos já foram vivenciados e vão constituir o chamado cuidado, no sentido de se preservar o que foi conquistado, e o sentimento de integridade. Isto pode ser expresso na capacidade do indivíduo em rever a sua trajetória de vida e apreciá-la, com algum grau de satisfação pois a integridade é a marca individual daqueles que conseguem aceitar e conviver com a sua própria trajetória de vida e defender o seu estilo peculiar, que representa o seu patrimônio maior, frente às ameaças e adversidades que a vida possa lhes reservar. Trata-se daquelas pessoas que conseguem vislumbrar a sua posição histórica e cultural, inserida num contexto e numa ordem maior Mais que isso, envelhecer bem como bem diz NERI (2000, p.13-14): "depende do delicado equilíbrio entre as limitações e as potencialidades do indivíduo, o qual the possibilitará lidar, em diferentes graus de eficácia, com as perdas inevitáveis do envelhecimento" .

\section{CONCLUSÕES}

Desde o inicio do estudo foi possível perceber o quanto é vasto e atraente o universo dos idosos que têm tanto a nos ensinar e contar e como retribuição, oferecemos ainda tão pouco. Resolvi então oferecer minha audição, minha visão e, principalmente, meu coração a um grupo da terceira idade que, rapidamente, sem pensar muito, não hesitou em me acolher com carinho e alegria.

As observações, a cada semana possibilitaram uma aproximação maior com os idosos e, mais tarde, durante as entrevistas, pude conhecê-los melhor. Nesses momentos eu me sentia emocionada ao ouvir as falas de cada um. Histórias sofridas, alegres, difíceis, melancólicas ou tímidas eram contadas sem poupar emoção, sem colocar restrições. Eram momentos de encontro, de se emocionar e compartilhar emoções e energias que proporcionavam uma sensação de bem-estar, de acolhimento e afeto.

Pouco a pouco, eles foram demonstrando como as emoções estavam presentes em suas vidas e como elas influenciavam o estado de equilíbrio, a saúde deles. Pude perceber quem era mais emoção, quem era mais razão e quem conseguia equilibrar melhor esses dois lados. Mas também tinham aqueles que buscavam um equilíbrio, algo difícil, pois emoção é algo que emerge, transborda e se lança como arco-íris, pleno de cores diversas, após a chuva de verão.
Chegar na terceira idade é viver em movimento contínuo, é caminhar pela vida, ultrapassar etapas, plantar, colher os frutos e saber que alguns desses frutos caíram da árvore antes da hora e não renderam o fruto esperado. É a espera do que vem pela frente, como quem espera ver e acredita em um futuro que está por vir, é plano e expectativa do que está por vir.

Assim, ao final desse estudo fica uma mensagem para a equipe multidisciplinar que tem como finalidade o cuidado ao idoso: que essa equipe seja plenamente "multi", reconhecendo as reais necessidades do idoso, proporcionando um cuidar mais humano. Aos enfermeiros e equipe de enfermagem, em especial, que (re)aprenda ou recupere o respeito às individualidades, incentivando as capacidades de cada idoso que esteja sob seu cuidado seja em hospitais, em lares especializados, em grupos de convivência ou em outros espaços de convivência. Finalmente, que os profissionais de saúde possam absorver de cada experiência com os idosos, as lições que eles ensinam para que assim, ao envelhecer eles saibam enfrentar melhor as mudanças, valorizando cada ruga no rosto e fio branco de cabelo como marcas de uma vida única. $E$ assim, no pêndulo das emoções que constituem o processo dinâmico de viver, vivendo, saibam lidar com as suas emoções para (re) aprender a importância de que é cuidando de si que se compreende melhor a importância da sua presença e envolvimento no cuidado com o outro.

\section{REFERÊNCIAS BIBLIOGRÁFICAS}

ADAMS, P. O amor é contagioso. 3. ed. Rio de Janeiro: Sextante, 1998.

BALLONE, G.J. Alterações Emocionais no Envelhecimento. PsiqWeb, Psiquiatria Geral. Disponível em: http://gballone.sites.uol.com.br/geriat/andropausa.html . 2002. [Acesso em 11 fev. 2006.

BARBOSA, J.S.O. Atividade física na terceira idade. In Veras, R. (org.) Terceira Idade: alternativas para uma sociedade em transição. Rio de Janeiro: Relume-Dumará: 1999. p. 149-160

BOFF, L. Saber cuidar: ética do humano - compaixão pela terra. Rio de Janeiro: Vozes, 1999.

GAUTHIER, J.H.M. Sociopoética: encontro entre arte, ciência e democracia na pesquisa em ciências humanas e sociais, enfermagem e educação. Rio de Janeiro: UFRJ/Editora EEAN, 1999.

GOLEMAN, D. Inteligência Emocional: a teoria revolucionária que redefine o que é ser Inteligente. Rio de Janeiro: Objetiva, 2001.

$\mathrm{KICKBUSCH}, \mathrm{I}$. El autocuidado en la promoción de la salud. In OPS. Promoción de la salud: una antologia Publicación Cientifica 557. Washington: OPS, 1996.

LIMA, C.A. As necessidades básicas e sua relação entre capacidade e bem-estar no cotidiano do idoso. 2003. 57 p. Trabalho de Conclusão de Curso de 
Graduação e Licenciatura em Enfermagem (Monografia). Escola de Enfermagem Aurora de Afonso Costa, Universidade Federal Fluminense. Niterói (RJ).

LÓPEZ, A.L; CIANCIARULLO, T.S. Compreendendo $o$ significado de qualidade de vida na velhice. Texto $e$ Contexto. Enferm. Florianópolis, v.8, n.3, p. 233-249, 1999.

NERI, A.L. (Org.). Qualidade de Vida e Idade Madura. 3. ed. Campinas, SP: Papirus, 2000. (Coleção Viva idade).

OLIVEIRA, M. de. Caminhando pela Vida: um estudo da visão do idoso frente ao envelhecer. 2003, 78p. Trabalho de Conclusão de Curso de Graduação e Licenciatura em Enfermagem (Monografia). Escola de Enfermagem Aurora de Afonso Costa, Universidade Federal Fluminense. Niterói (RJ).

PAPALEO NETTO, M. Geriatria: fundamentos, clínica, terapêutica. São Paulo: Atheneu, 1994.

PENNA, F.B. O Movimento das emoções na vida do idoso: um estudo com um grupo da terceira idade. 2004. 51p. Trabalho de Conclusão de Curso de Graduação e Licenciatura em Enfermagem (Monografia). Escola de Enfermagem Aurora de Afonso Costa, Universidade Federal Fluminense. Niterói (RJ).

PORTELLA, M.R. Grupos de Terceira Idade: a construção da utopia do envelhecer saudável. Passo Fundo: UFP, 2004.

RUIPÉREZ, I.; LLORENT, P. Geriatria. Guias Práticos de Enfermagem. Rio de Janeiro: McGrawHill, 1996.

RUSCHEL, A.E. O velho - Estranho sujeito do espelho. In: CASTRO, O. P. Envelhecer: Um encontro inesperado? Realidades e perspectivas na trajetória do envelhecente. Rio Grande do Sul: Notadez Informação e Universidade Tuiuti do Paraná, 2001. Cap. 2, p. 43-70

SCHIFFERLE, D. Aposentadoria e grupos de reflexão. In: NEGREIROS, T.C.G.M. A nova velhice: uma visão multidisciplinar. Rio de Janeiro: Revinter, 2003. Cap. 7, p. 89-100.

TEIXEIRA, E.R. O desejo e a necessidade no cuidado com o corpo: uma perspectiva estética de enfermagem. 1998. 198p. Tese (Doutorado). Escola de Enfermagem Anna Nery, Universidade Federal do Rio de Janeiro. Rio de Janeiro (RJ).

TEIXEIRA, MB. Empoderamento de idosos em grupos direcionados à promoção da saúde. 2002. 105 p. Dissertação (Mestrado). Fundação Oswaldo Cruz, Escola Nacional de Saúde Pública. Rio de Janeiro (RJ).

VICINI, G. Abraço afetuoso em corpo sofrido: saúde integral para idosos. São Paulo: Editora SENAC, 2002.

WALDOW, V.R. Cuidado Humano: O resgate necessário. Rio Grande do Sul: Sagra Luzzatto, 1998. 